\title{
Design And Drafting of Hvac, Central Air Conditioning System For An Office Building
}

\author{
K. Ratna Kumari ${ }^{1}$, A. Raji Reddy ${ }^{2}$, M. Vidya Sagar ${ }^{3}$ \\ ${ }^{1}$ Assistant Professor, Mechanical Department, Cmrtc, Jntuh, Hyderabad, Telangana, India \\ ${ }^{2}$ Professor \& Director, Cmrtc Mechanical Department, , Hyderabad, Telangana, India \\ ${ }^{3}$ Professor, Mechanical Department, Intuceh Hyderabad, Telangana, India
}

\begin{abstract}
The heating, ventilation, and air-conditioning (HVAC) system is arguably the most complex system installed in a building and is responsible for a substantial component of the total building energy use. A rightsized HVAC system will provide the desired comfort and will run efficiently. Right-sizing of an HVAC system is the selection of equipment and the design of the air distribution system to meet the accurate predicted heating and cooling loads of the house. Right-sizing the HVAC system begins with an accurate understanding of the heating and cooling loads on a space; however, a full HVAC design involves more than just the load estimate calculation; the load calculation is the first step of the iterative HVAC design procedure. This strategy guideline discusses the information needed to design the air distribution system to deliver the proper amount of conditioned air to a space. Heating and cooling loads are dependent upon the building location, sighting, and the construction of the house, whereas the equipment selection and the air distribution design are dependent upon the loads and each other.
\end{abstract}

Keywords: heating, ventilation, and air-conditioning (HVAC), air handling unit, refrigeration cycle, heat load estimation, u factor

\section{Introduction}

Many of the situations requiring mechanical ventilation also need a degree of air conditioning. To summarize, those situations most likely to require air conditioning are:

1. Rooms subject to high solar gains, such as south facing rooms especially those with large areas of glazing.

2. Rooms with high equipment densities such as computer rooms and offices which make extensive use of IT.

3. Rooms in which environment (temperature, dust or humidity) sensitive work is being carried out such as operation theatres and microprocessor manufacturing units.

\subsection{Basic Refrigeration cycle}

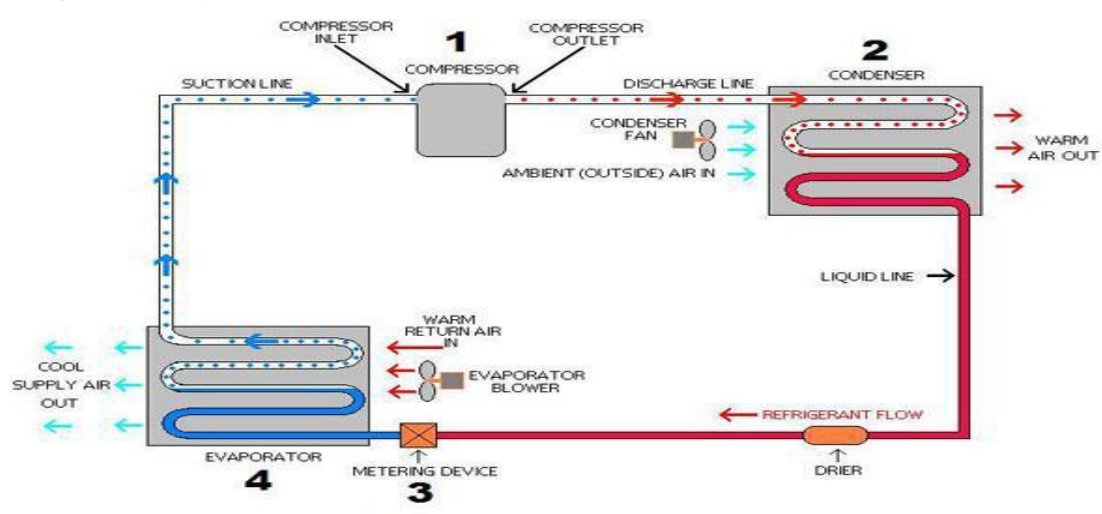

Fig: 1.1 Basic Refrigeration cycle

Compressor: An air compressor is a device that converts power (using an electric motor, diesel or gasoline engine, etc.) into potential energy stored in pressurized air (i.e., compressed air)

Condenser: A condenser is a device or unit used to condense a substance from its gaseous to it liquid state, by cooling it.in so doing, the latent heat is given by the substance, and will transfer to the condenser coolant.

Expansion Valve: A thermal expansion valve (often abbreviated as TEV, TXV, or TX valve) is a component in refrigeration and air conditioning systems that controls the amount of refrigerant flow into the evaporator thereby controlling the superheating at the outlet of the evaporator. 
Evaporator:An evaporator is a device used to turn liquid form of a chemical into its gaseous form. The liquid is a evaporated, or vaporized, into a gas.

\section{Components Of Air Handling Units Or Fan Coil Units}

As the name suggests air handling unit is the box type of unit that handles the room air. This article describes various parts of the air handling unit, its working and types.

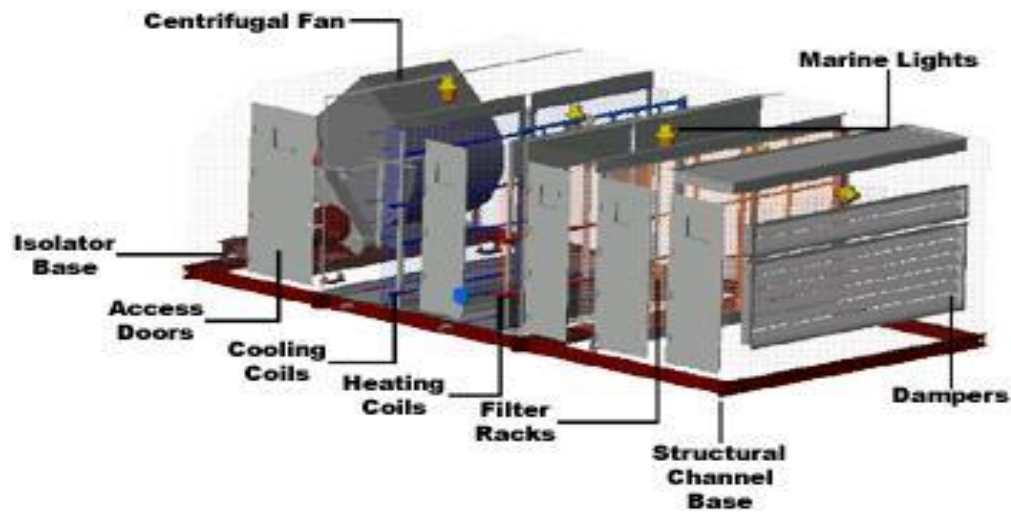

Fig: 2. 1 Air Handling unit

2.1 Box Enclosure: All the parts of the air handling unit are enclosed in the box type of enclosure. This ensures compactness of the unit and protection of all the components inside it. The whole box is insulated to prevent the loss of heat from the unit.

2.2 Cooling Coil: The cooling is one of the most important parts of the air handling units. It is made up of copper tubing of several turns and covered with the fins to increase the heat transfer efficiency of the cooling coil.

2.3 Ducts: The air handling is connected to the supply air and return air ducts. The supply air duct supplies the cool air from the air handling unit to various rooms, while the return air supplies hot return air from various rooms back to the air handling unit.

2.4 Fan or Blower: The fan or the blower sucks the hot return air from the room and blows it over cooling coil, cools it and sends it to the room to be air conditioned.

2.5 Air Filter: Air filter is one the important parts of any air conditioning system. The air filter removes dirt, dust, smoke and other impurities from the air and cleans. The air filter is usually attached to the cooling air and before it. The air is first absorbed or pushed over the air filter and then over the cooling coil.

\subsection{Heat Load Estimate:}

\section{Experimental Investigations}

The manner in which heat can flow can be any one or more for the following ways:

1. Solar radiation through transparent surfaces such as window.

2. Heat conduction through exterior wall/roof

3. Heat conduction through partitions, ceilings, floors of adjacent non-air conditioned spaces.

4. Heat generated internally by occupants, lights, appliances, equipments and process

5. Load due to intake of outside air for ventilation.

6. Other miscellaneous gains.

\subsubsection{Building Survey:}

1. Orientation of the Building

2. Application of the Space

3. Physical dimensions of the space

4. Ceiling height, floor to floor height, space above the false ceiling.

3.1.1.1 Load Estimation: The importance of accurate load calculations for air conditions design can never be over emphasized. In fact, it is the precision and care exercised by the designer in the calculation of the cooling load for summer and the heating load for winter that a trouble free, successful operation of air conditioning plant after installation would depend. 
3.1.1.2 Solar Heat Gain Through Glass: Glass, which is transparent, allows the sunrays to pass through it. This results in heat dissipation inside the room. The amount of heat dissipated into room depends upon the glass area that is exposed to sun

3.1.1.3 Solar Heat Gain Through Walls And Roofs: Heat gain through the exterior construction (walls and roof) is normally calculated at the time of greatest heat flow. It is caused by the solar heat being absorbed at the exterior surface and by the temperature difference between the outdoor and indoor air. The heat flow through the structure may then be calculated, using the steady state heat flow equation with equivalent temperature difference (ETD).

$\mathrm{Q}=\mathrm{U}^{*} \mathrm{~A} * \mathrm{ETD}$ where $\mathrm{Q}$ is heat flow rate in $(\mathrm{KJ} / \mathrm{Sec})$

$\mathrm{U}=$ transmission rate $(\mathrm{W} / \mathrm{Sq} . \mathrm{M} \mathrm{K})$

$\mathrm{A}=$ Area of surface $(\mathrm{Sq} \mathrm{m})$

ETD $=$ Equivalent Temperature Difference $(\mathrm{K})$

Heat loss through the exterior construction is normally calculated at the time of greatest heat flow.

3.1.1.4 Transmission Heat Gain Through Glass: This is heat gain that is obtained due to the difference in outside and inside conditions. The amount of heat that is transmitted through the glass into the room depends upon the glass area, temperature difference and transmission coefficient of glass. Here total glass irrespective of the direction is taken into consideration in total glass area.

3.1.1.5 Transmission Through Partitions And Walls: Heat gain here also depends upon the temperature difference between the outside and inside conditions, transmission coefficient and wall area exposed or partition wall area. Here the total area of the wall is taken irrespective of its direction. The temperature taken is generally $2^{\circ} \mathrm{C}$ less than the temperature gradient that is existing. Equivalent temperature difference is taken in these calculations.

3.1.1.6 Occupancy Load: Heat is generated within the human body by oxidation commonly called metabolic rate. The metabolic rate varies with the individuals and with his activity level. The amount of heat dissipated by the human body by radiation and convection is determined by the difference in temperature between the body surface and its surrounding. The heat dissipated by evaporation is determined by the difference in vapor pressure between body and the air. The metabolic rate is $85 \%$ for the male, and for children it is about $75 \%$. The excess heat and moisture brought in by people, where short time occupancy is occurring may increase heat gain from people by as much as $10 \%$.

3.1.1.7 Lighting: Lights generate sensible heat by the conversion of the electrical power input into light and heat. The heat is dissipated by radiation to the surrounding surfaces, by conduction into the adjacent materials and by convection to the surrounding air.

Fluorescent $=$ total light watts $* 1.25$

Incandescent $=$ total light watts

3.1.1.8 Appliances: Most applications contribute both sensible and latent heat to a space. Electric appliances contribute latent heat, only by virtue of the function they perform that is, drying, cooking, etc., whereas gas burning appliances, contribute additional moisture as a product of combustion. A properly designed hood with a positive exhaust system removes a considerable amount id the generated heat and moisture from most types of appliances.

3.1.1.9 Electric Motors: Electric motors contribute sensible heat to the space by converting the electrical power input to heat. Some of this power is dissipated as heat in the motor frame and can be evaluated as: Input*(1-motor efficiency)

3.1.1.10 System Heat Gain: The system heat gain is considered as the heat added to or lost by the system components, such as the ducts, piping, air conditioning fan and pump etc. this heat gain must be estimated and included in the load estimate but can be accurately evaluated only after the system has been designed.

3.1.1.11 Heat Gain From Outside Air: To estimate the infiltration of air into the conditioned space, the crack method is considered to become more accurate. The leakage of air is a function of wind pressure difference $\mathrm{P}$, which is determined by the equation:

$$
\mathrm{dp}=0.00470 \mathrm{C}^{2}
$$

Where $\mathrm{dp}$ is in the $\mathrm{cm}$ of $\mathrm{WG}$ and $\mathrm{C}$ is in $\mathrm{Km} / \mathrm{hr}$ is the local wind velocity. Tables are available for infiltration in $\mathrm{m} / \mathrm{hr} / \mathrm{m}$ of crack for different dp values. After the calculation of all these components of room loads, the room sensible heat and the room latent heat are determined.

\subsection{Determination of $U$ factor:}

\section{Experimental Results}

The conduction heat transfer through the walls or roof will depend on its thickness and the thermal conductivity of the material used. In addition, there will be convection and radiation from both the outside 
and inside surfaces. Hence, the steady state heat transfer is expressed in terms of an overall heat transfer coefficient $U$ and the overall temperature difference between the outside and inside. Also a wall may be composite, consisting of many sections of different construction and insulating materials. For this purpose, all the layers of different materials of varying thickness ' $\mathrm{X}$ ' and thermal conductivity ' $\mathrm{K}$ ' are to be taken into consideration.

The cross section of the wall, considered for this building with thickness,

Table 4.1.1 Densities And Thermal Conductivities

Film coefficients of air on the outside and inside wall can be calculated from the following formula $\mathrm{h}=$

\begin{tabular}{|l|l|l|l|}
\hline Materials Kg/Cu.m & Thickness(M) & Thermal Conductivity (K) & Density(W/MK) \\
\hline Brick & 0.2286 & 1.32 & 2000 \\
\hline Cement Plaster & 0.0127 & 11.77 & 1885 \\
\hline
\end{tabular}

$(11.42+0.95 * \mathrm{v}) \mathrm{W} / \mathrm{Sq} . \mathrm{M} \mathrm{K}$

where $\mathrm{v}$ is in $\mathrm{km} / \mathrm{hr}$

The velocity of outside air for HYDERABAD city is taken as $12.5 \mathrm{kmph}$ and the inside velocity is considered as $0.483 \mathrm{kmph}$.

Therefore,

ho $=(11.42+0.95 * 12.5)=23.3 \mathrm{~W} / \mathrm{Sq} . \mathrm{M} \mathrm{K}$

hi $=(11.42+0.95 * 0.483)=12.038 \mathrm{~W} / \mathrm{Sq} . \mathrm{M} \mathrm{K}$

If $\mathrm{U}_{\mathrm{w}}$ is the $\mathrm{U}$ factor for the wall,

$1 / \mathrm{U}_{\mathrm{w}}=1 / \mathrm{h}_{\mathrm{o}}+\mathrm{X}_{\mathrm{p}} / \mathrm{k}_{\mathrm{p}}+\mathrm{X}_{\mathrm{b}} / \mathrm{k}_{\mathrm{b}}+\mathrm{X}_{\mathrm{p}} / \mathrm{k}_{\mathrm{p}}+1 / \mathrm{h}_{\mathrm{i}}$

$=1 / 23.3+0.0127 / 11.27+0.0127 / 1.32+0.0127 / 11.27+1 / 12.038$

$=0.357$

$\mathrm{U}_{\mathrm{w}}=2.8 \mathrm{~W} / \mathrm{Sq} \cdot \mathrm{M} \mathrm{K}$.

If $\mathrm{U}_{\mathrm{p}}$ is the $\mathrm{U}$ factor for the partition wall,

$1 / \mathrm{U}_{\mathrm{p}}=1 / \mathrm{h}_{\mathrm{o}}+\mathrm{X}_{\mathrm{p}} / \mathrm{k}_{\mathrm{p}}+\mathrm{X}_{\mathrm{b}} / \mathrm{k}_{\mathrm{b}}+\mathrm{X}_{\mathrm{p}} / \mathrm{k}_{\mathrm{p}}+1 / \mathrm{h}_{\mathrm{i}}$

$=1 / 23.3+0.0127 / 11.27+0.2286 / 1.32+0.0127 / 11.27+1 / 12.038$

$=0.309$

$\mathrm{U}_{\mathrm{p}}=3.23 \mathrm{~W} / \mathrm{Sq} \cdot \mathrm{M} \mathrm{K}$.

Table 4.1.2 The Position Of The Rcc Slab And The Insulation Used Along The Thinness

\begin{tabular}{|l|l|l|l|}
\hline Materials Kg/Cu.m & Thickness(M) & Thermal Conductivity (K) & Density(W/MK) \\
\hline RCC slab & 0.2 & 9 & 1920 \\
Asbestos or insulating board & 0.04 & 0.154 & $470-570$ \\
\hline
\end{tabular}

If $\mathrm{U}_{\mathrm{r}}$ is the $\mathrm{U}$ factor for the roof

$$
\begin{aligned}
1 / \mathrm{U}_{\mathrm{r}}= & 1 / \mathrm{h}_{\mathrm{o}}+\mathrm{X}_{\mathrm{p}} / \mathrm{k}_{\mathrm{p}}+\mathrm{X}_{\mathrm{b}} / \mathrm{k}_{\mathrm{b}}+\mathrm{X}_{\mathrm{p}} / \mathrm{k}_{\mathrm{p}}+1 / \mathrm{h}_{\mathrm{i}} \\
& =1 / 23.3+0.20 / 9+0.05 / 0.154+1 / 12.038 \\
& =0.469 \\
\mathrm{U}_{\mathrm{p}}= & 2.13 \mathrm{~W} / \text { Sq.M K. }
\end{aligned}
$$

\subsection{Determation Of Equivalent Temperature Differentials:}

When There Is Departure From These Conditions, The Following Corrections May Be Applied:

The valves of $t_{o}$ and $t_{i}$ are additive to $t_{e}$. Hence add or subtract the difference of $\left(t_{o}-t_{i}\right)$ and $8.3^{\circ} \mathrm{C}$ If the daily range is different from $11.1^{\circ} \mathrm{C}$, then apply corrections as follows:

a) For each $1^{\circ} \mathrm{C}$ difference less than $11.1^{\circ} \mathrm{C}$, add $0.25^{\circ} \mathrm{C}$ for medium construction $\&$ add $0.5^{\circ} \mathrm{Cfor}$ heavy construction..

b) For each $1^{\circ} \mathrm{C}$ difference greater than $11.1{ }^{\circ} \mathrm{C}$, subtract $0.25^{\circ} \mathrm{C}$ for medium construction \& subtract $0.5^{\circ} \mathrm{C}$ for heavy construction..

For the Hyderabad city, the solar radiation will be maximum at $4.00 \mathrm{pm}$ and an average temperature of $41.1^{\circ} \mathrm{C}$ has been considered. And the daily range will be around $10^{\circ} \mathrm{C}$.

Table 4.2.1basis of design outside ambient codiitions:

\begin{tabular}{|l|l|l|}
\hline Season & DBT & WBT \\
\hline Summer & $42^{0} \mathrm{c}$ & $25.6^{0} \mathrm{c}$ \\
\hline Monsoon & $30^{0} \mathrm{c}$ & $27.5^{0} \mathrm{c}$ \\
\hline Winter & $12.5^{0} \mathrm{c}$ & $8.6^{0} \mathrm{c}$ \\
\hline
\end{tabular}




\subsection{Design Inside Conditions In Airconditioned Area:}

\subsubsection{Psychrometric Calculations:}

In this chapter the method of loading calculation is presented for area of clean rooms for different inside conditions. Heat load calculations for rooms, which need comfort conditions, are also presented. All the heat loads calculation charts are presented in the appendix. The load calculations of typical clean rooms, which differ in size of particulate, amount of filtration required, and class to be maintained are only discussed. The area that needs comfort condition is also discussed.

\section{Discussion Of Results}

5.1 Ducting Measurement, Acoustic\& Thermal Insulation Sheet:

\begin{tabular}{|c|c|c|c|c|c|c|c|c|c|c|}
\hline SI.No. & W & H & L & Qnty. & Type & Area & 24 & 22 & Acoustic & Thermal \\
\hline & (mm) & $(\mathrm{mm})$ & $(\mathrm{mm})$ & & & Sq.Mts. & Gauge & Gauge & Insulation & Insulation \\
\hline \multicolumn{11}{|c|}{ LINE-1 } \\
\hline 1 & 1200 & 250 & 1200 & 1 & STP & 3.48 & 0 & 3.48 & 3.48 & 0 \\
\hline 2 & 1200 & 250 & 2500 & 1 & ELBOW & 7.25 & 0 & 7.25 & 7.25 & 0 \\
\hline 3 & 1200 & 250 & 2536 & 2 & STP & 14.71 & 0 & 14.71 & 0 & 0 \\
\hline 4 & 1075 & 250 & 300 & 1 & TAPPER & 0.8 & 0 & 0.8 & 0 & 0 \\
\hline 5 & 950 & 250 & 2000 & 1 & ELBOW & 4.8 & 0 & 4.8 & 0 & 0 \\
\hline 6 & 950 & 250 & 1600 & 1 & STP & 3.84 & 0 & 3.84 & 0 & 0 \\
\hline 7 & 950 & 250 & 2150 & 1 & ELBOW & 5.16 & 0 & 5.16 & 0 & 0 \\
\hline 8 & 875 & 250 & 900 & 1 & TAPPER & 2.03 & 0 & 2.03 & 0 & 0 \\
\hline 9 & 800 & 250 & 1500 & 1 & STP & 3.15 & 0 & 3.15 & 0 & 0 \\
\hline 10 & 800 & 250 & 2100 & 1 & STP & 4.41 & 0 & 4.41 & 0 & 0 \\
\hline 11 & 725 & 250 & 300 & 1 & TAPPER & 0.59 & 0.59 & 0 & 0 & 0 \\
\hline 12 & 650 & 250 & 2000 & 1 & STP & 3.6 & 3.6 & 0 & 0 & 3.6 \\
\hline 13 & 650 & 250 & 1200 & 1 & STP & 2.16 & 2.16 & 0 & 0 & 2.16 \\
\hline 14 & 750 & 350 & 0 & 1 & DUMMY & 0.26 & 0 & 0.26 & 0 & 0.26 \\
\hline
\end{tabular}

\subsection{Table Diffuser Selection Chart:}

\begin{tabular}{|c|c|c|c|c|c|c|c|c|c|}
\hline \multicolumn{70}{|c|}{ DIFFUSER SELECTION CHART } \\
\hline Diffuser Size(MM) & \multicolumn{2}{|c|}{ Diffuser Size(") } & Diffuser & \multicolumn{1}{l|}{ Diffuser } & Diffuser & \\
\hline W & D & W X D & Fpm & Efficiency & CFM & Efficiency & CFM & Efficiency & CFM \\
\hline 150 & 150 & $6 " X 6 "$ & 500 & 0.40 & 48 & 0.60 & 73 & 0.75 & 91 \\
\hline 225 & 150 & $9 " X 6 "$ & 500 & 0.40 & 73 & 0.60 & 109 & 0.75 & 136 \\
\hline 300 & 150 & $12 " X 6 "$ & 500 & 0.40 & 97 & 0.60 & 145 & 0.75 & 182 \\
\hline 375 & 150 & $15 " X 6 "$ & 500 & 0.40 & 121 & 0.60 & 182 & 0.75 & 227 \\
\hline 450 & 150 & $18 " X 6 "$ & 500 & 0.40 & 145 & 0.60 & 218 & 0.75 & 272 \\
\hline 525 & 150 & $21 " X 6 "$ & 500 & 0.40 & 169 & 0.60 & 254 & 0.75 & 318 \\
\hline 600 & 150 & $24 " X 6 "$ & 500 & 0.40 & 194 & 0.60 & 291 & 0.75 & 363 \\
\hline 675 & 150 & $27 " X 6 "$ & 500 & 0.40 & 218 & 0.60 & 327 & 0.75 & 409 \\
\hline 750 & 150 & $30 " X 6 "$ & 500 & 0.40 & 242 & 0.60 & 363 & 0.75 & 454 \\
\hline 825 & 150 & $33 " X 6 "$ & 500 & 0.40 & 266 & 0.60 & 399 & 0.75 & 499 \\
\hline 900 & 150 & $36 " X 6 "$ & 500 & 0.40 & 291 & 0.60 & 436 & 0.75 & 545 \\
\hline
\end{tabular}




\subsection{Total Heat \& Cooling Capacity}

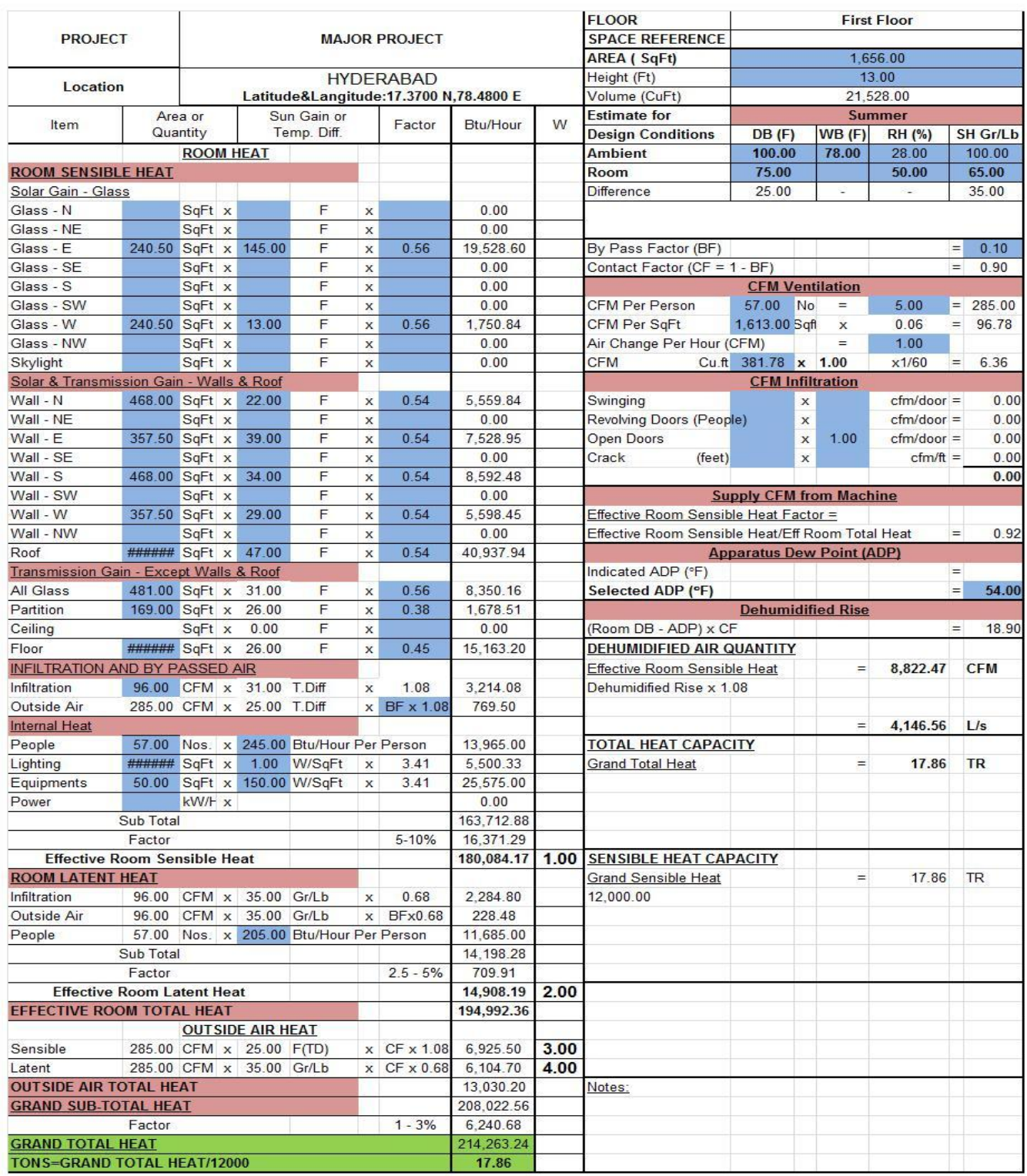

\subsection{Plant Layout:}

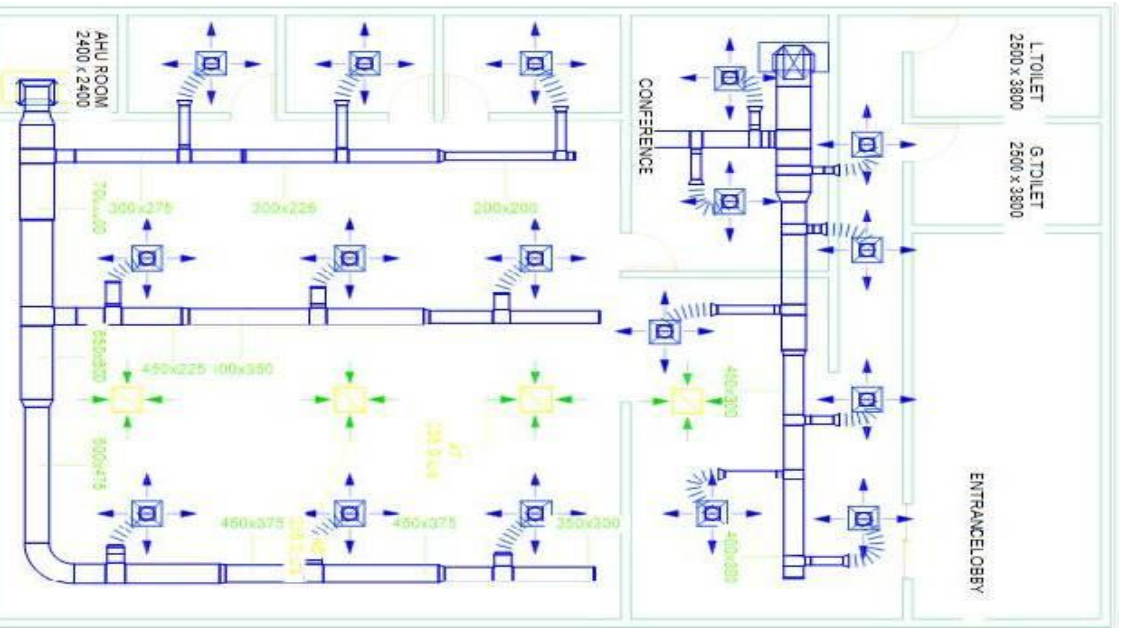




\section{Conclusion}

The rate of change in our industry will be exponential. Some changes will be caused by improvements in technology whereas others will be the result of influences outside our immediate control. As engineers, we have an obligation to be proactive in encouraging changes that are of benefit to the society we serve. This in turn will have direct benefit to our industry and to each of us individually. You can be part of that positive change by sharing your knowledge with other engineers through publications, serving with standard writing organizations and participating in technical societies. We are a "people-oriented" profession. Our designs have a direct impact on the people who occupy our buildings. We will continue to discover ways to assure their comfort and health, while reducing our impact on the environment and natural resources. Changes will occur and for the better. Our vision for our industry can be fulfilled as we take action through our contributions to the technology of HVAC.

\section{References}

[1]. IEA (International Energy Agency), Energy Balances of OECD Countries - 2010edition, Paris, 2010.

[2]. L. Pérez-Lombard, et al., A review of benchmarking, rating and labelling con-cepts within the framework of building energy certification schemes, Energyand Buildings 41 (2009) 272-278.

[3]. R. Bartlett, et al., Understanding Building Energy Codes and Standards, PacificNorthwest National Laboratory, 2003.

[4]. L. Pérez-Lombard, et al., A review on buildings energy consumption informa-tion, Energy and Buildings 40 (3) (2008) 394-398.

[5]. J. Lausten, Energy Efficiency Requirements in Building Codes, Energy EfficiencyPolicies for New Buildings, International Energy Agency, Paris, 2008.

[6]. M. Evans, et al., Shaping the energy efficiency in new buildings: A Comparisonof Building Energy Codes in the Asia-Pacific Region, Pacific Northwest National Laboratory, 2009.

[7]. Asia Business Council, Status of Energy Efficient Building Codes in Asia, 2007.

[8]. ENPER-TEBUC, Energy performance of buildings, Calculation Procedures Usedin European Countries, 2003.

[9]. AustralianBuildingCodesBoard,InternationalSurveyofBuildingEnergyCodes, Australian Greenhouse Office, Canberra, 2000.

[10]. K.B. Janda, J.F. Busch, Worldwide status of energy standards for buildings, Energy 19 (1) (1994) $27-44$.

[11]. K.B. Janda, Worldwide status of energy standards for buildings: a 2007 update,Proceedings of The Fifth Annual Improving Energy Efficiency in Commercial Buildings (IEECB), Frankfurt, Germany, April, 2008.

[12]. J.C. Lam, C.M. Hui, A review of building energy standards and implications for

[13]. Hong Kong, Energy and Buildings 22 (1) (1995) 25-43.

[14]. ASHRAE Standard 90-1975, Energy Conservation in New Building Design, American Society of Heating, Refrigerating and AirConditioning Engineers, Atlanta, GA, 1975. 